\title{
The Prevalence and Risk Factors of Migraine Among the Selected High School Students
}

\author{
Julie Vanlalsawmi and Deeplata Mendhe \\ Department of Community Health Nursing, Smt. RadhikabaiMeghe Memorial College of Nursing, Datta Meghe \\ Institute of Medical Sciences Sawangi, Wardha, Maharashtra, India. \\ Corresponding author email: juliehermanos0@gmail.com
}

\section{ABSTRACT}

Migraine is one of the most common aetiologies for headache. This very common neurological disorder has a significant impact on patients' quality of life. Communitybased epidemiological studies are scarce in India and other developing countries. As India is multi-ethnic, it is essential to determine the prevalence of headache and its subtypes in other regions also. Information about headache disorders is insufficient and variable, although migraine was identified to be more common in the rural population.. To assess the prevalence of migraine among the students of selected high school. 2. To assess the risk factors of migraine among the students of selected high school. 3. To associate the prevalence and risk factors of migraine among the students of selected high school with a selected demographic variable. Quantitative Research Approach. Descriptive Research Design. The study was conducted at School of Scholars, Sawangi (M) Wardha; Alphonsa Sr. High School, Sawangi (M) Wardha and Model High School, Salod, Wardha. Population- High School students. Non-Probability Sampling Technique. 314. The study shows that the Prevalence of migraine was $10.83 \%$. Mean migraine score was $2.27 \pm 1.81$ which is higher than the level of significance. While dealing with the distribution of subjects with their demographic variables, the prevalence of migraine is statistically associated with the father's educational status ( $p=0.006)$, family history of migraine $(p=0.001)$ and gender $(p=0.026)$. In this study the findings of the study shows that there is no significant association of risk factors of migraine with the demographic variables like age, class, family income, type of family, residence and mother's educational qualification; but there is a significant relationship with the gender, father's educational qualification and family history of migraine.

\section{KEY WORDS: ASSESS, PREVALENCE, MIGRAINE, HIGH SCHOOL STUDENTS}

\section{INTRODUCTION}

Migraine is one the oldest ailments known to mankind. Some of the earliest cases of painful headaches were recorded by the ancient Egyptians and date back as far as 1200 B.C. Much later, in around 400 B.C., Hippocrates referred to the visual disturbances that can precede a migraine such as flashing lights or blurred vision, which we call aura. He also described the relief felt by sufferers after vomiting (Assadi et al., 2012).

Biosc Biotech Res Comm P-ISSN: 0974-6455 E-ISSN: 2321-4007

\section{crossef}

Identifiers and Pagination

Year: 2021 Vol: 14 No (9) Special Issue

Pages: $330-333$

This is an open access article under Creative

Commons License Attribn 4.0 Intl (CC-BY).

DOI: $h t t p: / / d x$.doi.org/10.21786/bbrc/14.9.60
The word migraine was derived from the Latin word "hemicrania" meaning "half" (hemi) "skull" (crania). This term was first used by Galenus of Pergamon to describe the pain felt across one side of the head during a migraine. He also suggested that the pain originated in the meninges and vasculature of the head. In addition, he pointed towards a connection between the stomach and the brain due to the vomiting that seemed to be related to migraines (Assadi et al., 2012).

Migraine is a brain disorder most clearly manifested by headache. The two major forms are distinguished based on headache frequency: episodic migraine (EM) and chronic migraine (CM). The revised second International Classification of Headache Disorders (ICHD-IIR) defines CM as having 15 or more headache-days per month for 3 months, with at least eight headaches per month linked to migraine without aura, either by virtue of meeting a case definition or by response to migraine-specific treatment (Assadi et al., 2012).
Article Information

Received: $13^{\text {th }}$ Apr 2021

ccepted after revision: $09^{\text {th }}$ June 2021 
EM is characterized by headache on $<15$ days per month with one or more attacks fulfilling ICHD-II criteria. CM affects approximately 1-2\% of the worldwide population and has a significantly greater effect on quality of life than EM. CM patients are more debilitated and more likely to miss work or have decreased productivity. CM patients have more comorbid conditions, including psychiatric and pain disorders. They also use more health resources than EM patients, including emergency department (ED) visits, clinic visits and medications.

Statement of the Problem: Assess the prevalence and risk factors of migraine among the students of selected high school (Lipton et al., 2011).

Figure 1: Assessment with level of prevalence of migraine

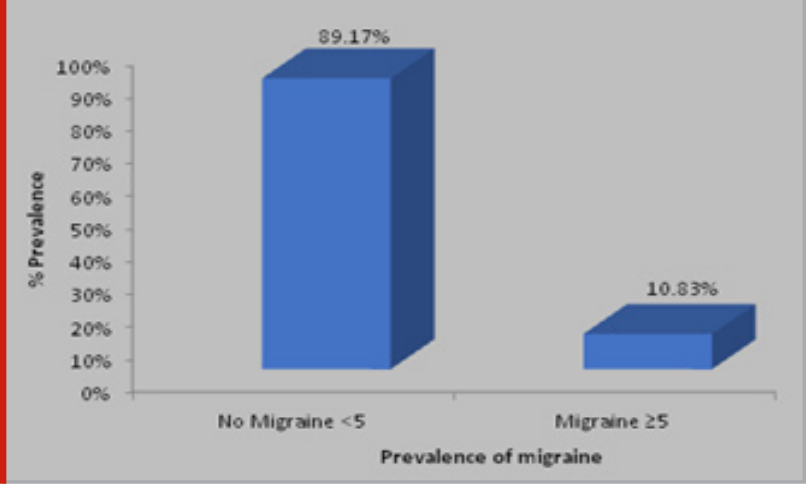

Objectives of the Study: To assess the prevalence of migraine among the students of selected high school. To assess the risk factors of migraine among the students of selected high school. To associate the prevalence and risk factors of migraine among the students of selected high school with a selected demographic variable.

\section{Hypothesis}

$\mathbf{H}_{\mathbf{1}}$ : There is significant association between prevalence and risk factors of migraine among the students of selected high school with their selected demographic variables (Lipton et al., 2011).

$\mathbf{H}_{0}$ : There is no significant association between prevalence and risk factors of migraine among the students of selected high school with their selected demographic variables (Lipton et al., 2011).

\section{MATERIAL AND METHODS}

314 samples of high school students were selected by Non-Probability convenience sampling technique in selected high schools of Wardha. The inclusion criteria were: a) High school students who are present at the time of data collection. b) High school students who are willing to participate. The exclusion criteria were: a) High school students who have already attended the programme on the same topic. b) High school students who are not willing to participate at the study. In this study, Descriptive Research Design was used. The tool used were Bilirubinometer and Serum estimation. The data gathering process began from 1st-20th November 2020. The investigator visited selected high schools in advance and obtained the necessary permission from the concerned authorities (Lipton et al., 2011).

Statistical Analysis: Based on the objectives and the hypothesis the data were analyzed and interpreted by SPSS software (Assadi et al., 2012).

Table 1 . Assessment with level of prevalence of migraine $n=314$

\begin{tabular}{|c|c|c|c|c|c|}
\hline Sl.no & Characteristics & Yes & $\%$ & No & $\%$ \\
\hline 1. & Intensity (Mild to moderate) & 96 & 30.57 & 218 & 69.43 \\
\hline 2. & Duration (4-72 hours) & 62 & 19.75 & 252 & 80.25 \\
\hline 3. & Frequency (3-5 times/month) & 88 & 28.03 & 226 & 71.97 \\
\hline 4. & Location (unilateral) & 60 & 19.11 & 254 & 80.89 \\
\hline 5. & Quality (throbbing) & 100 & 31.85 & 214 & 68.15 \\
\hline 6. & Aggravation & 93 & 29.62 & 221 & 70.38 \\
\hline 7. & Photophobia & 95 & 30.25 & 219 & 69.75 \\
\hline 8. & Phonophobia & 56 & 17.83 & 258 & 82.17 \\
\hline 9. & Vomiting + nausea & 64 & 20.38 & 250 & 79.62 \\
\hline & No Migraine $<5$ & \multicolumn{4}{|c|}{$280(89.17 \%)$} \\
\hline & Migraine $\geq 5$ & \multicolumn{4}{|c|}{$34(10.83 \%)$} \\
\hline & Mean \pm SD & \multicolumn{4}{|c|}{$2.27 \pm 1.81(0$ to 8$)$} \\
\hline
\end{tabular}

Study Approval: Approvals were obtained from the following: Institutional Ethics Committee, Datta Meghe Institute of Medical Sciences (Deemed to be University) with reference No. DMIMS(DU)/IEC/2018-19/9767, Chief Medical Superintendent, AVBRH, Sawangi(M), Wardha and informed consent has been taken from the patient's parents (Assadi et al., 2012).

\section{RESULTS AND DISCUSSION}

The data obtained to describe the sample characteristics including demographic variables (age, gender, class, residence, family income, type of family, mother's educational qualification, father's educational qualification, family history of migraine, already diagnosed with migraine), prevalence of migraine among 
the high school students and the associated risk factors of migraine. The study shows that $30.57 \%$ of the high school students had mild to moderate intensity of headache, $19.75 \%$ had headache duration lasting for about 4-72 hours, 28.03\% had frequency 5-9 times of headache per month, 19.11\% had unilateral location of pain in head,
$31.85 \%$ had throbbing quality of pain, $29.62 \%$ had report that the headache is aggravated by some factors, $30.25 \%$ had photophobia and $20.38 \%$ of the high school students had nausea and vomiting. Minimum prevalence score in was 0 and maximum score in was 8 .

Table 2. Assessment of migraine with level of lifestyle characteristics

\begin{tabular}{|c|c|c|c|c|c|}
\hline Sl. No & Characteristics & Yes & $\%$ & No & $\%$ \\
\hline 1. & Do you have the habit of sleeping late unnecessarily? & 34 & 100.00 & 0 & 0.00 \\
\hline 2. & Will your daily water intake be a minimum of 1.5litres? & 8 & 23.53 & 26 & 76.47 \\
\hline 3. & Do you frequently skip meals? & 5 & 14.71 & 29 & 85.29 \\
\hline 4. & Do you have the habit of fasting? & 19 & 55.88 & 15 & 44.12 \\
\hline 5. & $\begin{array}{c}\text { Do you have the habit of consuming tea or other caffeinated drink } \\
\text { regularly? }\end{array}$ & 16 & 47.06 & 18 & 52.94 \\
\hline 6. & Do you smoke? & 3 & 8.82 & 31 & 91.18 \\
\hline 7. & Do you consume tobacco or other gutkha products? & 3 & 8.82 & 31 & 91.18 \\
\hline 8. & $\begin{array}{c}\text { Do you have the habit of regular watching of Television, Computer, } \\
\text { Mobile phone? }\end{array}$ & 26 & 76.47 & 8 & 23.53 \\
\hline 9. & $\begin{array}{c}\text { Do you spend more than 2 hours continuous watching TV, } \\
\text { Computers, Mobile phone etc in a day? }\end{array}$ & 34 & 100.00 & 0 & 0.00 \\
\hline 10. & Do you consume alcohol? & 0 & 0.00 & 34 & 100.00 \\
\hline
\end{tabular}

Table 3. Assessment of migraine with level of environmental characteristics $n=34$

\begin{tabular}{|c|c|c|c|c|c|}
\hline Sl. No & Environmental Characteristics & Yes & $\%$ & No & $\%$ \\
\hline 1. & Is your living condition prone for too much sun exposure? & 15 & 44.12 & 19 & 55.88 \\
\hline 2. & Is your living area free from pollution? & 17 & 50.00 & 17 & 50.00 \\
\hline 3. & Is your home lighting condition sufficient for you to study? & 8 & 23.53 & 26 & 76.47 \\
\hline 4. & Do you require long distance travel from your home to reach school? & 16 & 47.06 & 18 & 52.94 \\
\hline
\end{tabular}

Table 4. Assessment of migraine with level of health characteristics

\begin{tabular}{|c|c|c|c|c|c|}
\hline Sl. No & Health Characteristics & Yes & $\%$ & No & $\%$ \\
\hline 1. & Stress & 18 & 52.94 & 16 & 47.06 \\
\hline 2. & Diabetes Mellitus & 2 & 5.88 & 32 & 94.12 \\
\hline 3. & Hypertension & 1 & 2.94 & 33 & 97.06 \\
\hline 4. & Cardiac Disease & 0 & 0.00 & 34 & 100.00 \\
\hline 5. & Visual defect & 18 & 52.94 & 16 & 47.06 \\
\hline 6. & Seizure & 0 & 0.00 & 34 & 100.00 \\
\hline
\end{tabular}

Mean migraine score was 2.27 \pm 1.81 . Prevalence of migraine was $10.83 \%$. While dealing with section A, distribution of subjects with their demographic variables, the prevalence of migraine is statistically associated with the father's educational status $(p=0.006)$, family history of migraine $(p=0.001)$ and gender $(p=0.026)$. Hence, it is interpreted that if the status of the father's educational qualification is high or in average, it may overall contribute to the low risk of occurrence of migraine among their children. Also, children who are having family history of migraine are likely to develop migraine in their later life. The study also interprets that girl are likely to have migraine as compared to boys in relation to different hormonal factors and environmental factors (Philipp et al., 2019).
Present study reported the prevalence of migraine among 314 high school students in selected schools. In this study, Descriptive Research Design was adopted. International Headache Society classification of migraine criteria was adopted to assess the prevalence of migraine in which students scoring 5 points and above $(5 \geq)$ are classified under students having migraine, while students scoring below 5 points $(5<)$ are regarded not to have migraine. In this study, the prevalence rate of migraine among the high school students of selected schools is found out to be $10.83 \%$. Present study shows that the prevalence of migraine is statistically associated with the father's educational status $(p=0.006)$; the prevalence of migraine is statistically associated with the family history of 
migraine $(p=0.001)$; the prevalence of migraine is statistically associated with the gender $(p=0.026)$.

\section{CONCLUSION}

In this study the findings of the study shows that there is no significant association of risk factors of migraine with the demographic variables like age, class, family income, type of family, residence and mother's educational qualification; but there is a significant relationship with the gender, father's educational qualification and family history of migraine.

\section{ACKNOWLEDGEMENTS}

We would like to thank them for their kind cooperation.

\section{Conflict of interest: Nil}

\section{Financial support: Nil}

\section{REFERENCES}

Assadi M, Zerafati G, Dham BS, Contreras L, Akbar U, Zayas L, Leone P. (2012 Jan) The prevalence, burden and cognizance of migraine in adolescent girls. Journal of Pediatric Neurology. 1;10(1):29-34.

Lipton RB, Manack A, Ricci JA, Chee E, Turkel CC, Winner P. (2011 May) Prevalence and burden of chronic migraine in adolescents: Results of the chronic daily headache in adolescents' study (C-dAS). Headache: The Journal of Head and Face Pain.;51(5):693-706.

Philipp J, Zeiler M, Wöber C, Wagner G, Karwautz AF, Steiner TJ, Wöber-Bingöl Ç. (2019 Dec Prevalence and burden of headache in children and adolescents in Austria-A nationwide study in a representative sample of pupils aged 10-18 years. The journal of headache and pain ;20(1):1-2. 